\title{
Obesity in young age is a risk factor for preeclampsia: a facility based case-control study, northwest Ethiopia
}

\author{
Mulualem Endeshaw ${ }^{2}$, Fantu Abebe ${ }^{1 *}$, Solomon Worku ${ }^{3}$, Lalem Menber ${ }^{4}$, Muluken Assress ${ }^{5}$ and Muluken Assefa ${ }^{6}$
}

\begin{abstract}
Background: Preeclampsia is one of the most commonly encountered hypertensive disorders of pregnancy. For many years, obesity has been suggested to play a role in preeclampsia. However, the hypotheses have been diverse and often revealed inconsistent results. This study has aimed to estimate the effect of obesity and dietary habits on preeclampsia in Bahir Dar City, north-western Ethiopia.
\end{abstract}

Methods: A facility-based unmatched case-control study was conducted on 453 (151 cases and 302 controls) pregnant women, attending antenatal care or skilled delivery at Bahir Dar City. Data were collected through face to face interviews and measurements of mid-upper-arm circumference (MUAC) at the time of the interviews. Data were cleaned and entered into IBM SPSS version 20 and later analyzed using STATA version 12. Univariate and multivariate logistic regression analyses were employed to estimate the effect of independent variables on preeclampsia. Stratified analysis was conducted to check for presence of confounding and/or effect modification between covariates.

Result: The odds of preeclampsia were higher among obese (MUAC $\geq 25 \mathrm{~cm}$ ) women than their leaner counterparts $(A O R=3.33,95 \% \mathrm{Cl}: 1.87,5.79)$. Obesity was also found to have a similar magnitude of risk for late onset preeclampsia $(A O R=3.63,95 \% \mathrm{Cl}: 1.89,6.97)$. When stratified by age, the effect of obesity on overall and late onset preeclampsia was significant among young (age <35 years) women $(\mathrm{COR}=1.81,95 \% \mathrm{Cl}: 1.11,2.99)$ and $(\mathrm{COR}=2.09,95 \% \mathrm{Cl}$ : 1.16, 3.86), respectively. As the age groups became more homogenous through adjusted stratification, obesity showed a particularly significant effect in women age $\leq 24$ and $25-29$ years; ( $A O R=2.31,95 \% \mathrm{Cl}: 1.06,5.12)$ and $(\mathrm{AOR}=3.66$, $95 \%$ Cl: $1.37,10.87)$ respectively. Similarly, the effect of obesity on late onset preeclampsia was evident among younger women age $\leq 24$ and $25-29$ years; $(A O R=3.16,95 \% \mathrm{Cl}: 1.21,8.24)$ and $(A O R=1.98,95 \% \mathrm{Cl}: 1.16,3.40)$ respectively. However, obesity has no significant effect on early onset of preeclampsia (AOR $=1.98,95 \% \mathrm{Cl}: 0.79,4.94$ ). On the other hand, compliance to folate supplementation during pregnancy and fruit consumption were associated with reduced risk of preeclampsia.

Conclusion: Obesity in young age was found to be a risk factor for preeclampsia while compliance to folate supplement and adequate fruit consumption were found to be protective against preeclampsia. Promoting healthy life style, including body weight control, consumption of fruits and vegetables, and folate supplementation should be promoted to reduce the risk of preeclampsia.

Keywords: Preeclampsia, MUAC, Obesity, Compliance

\footnotetext{
* Correspondence: fantuabebe@gmail.com

${ }^{1}$ Pre-service Education of Health Professionals, International

Non-Governmental Organization, P.O. Box, 1566, Bahir Dar, Ethiopia

Full list of author information is available at the end of the article
}

(c) 2016 The Author(s). Open Access This article is distributed under the terms of the Creative Commons Attribution 4.0 International License (http://creativecommons.org/licenses/by/4.0/), which permits unrestricted use, distribution, and reproduction in any medium, provided you give appropriate credit to the original author(s) and the source, provide a link to the Creative Commons license, and indicate if changes were made. The Creative Commons Public Domain Dedication waiver (http://creativecommons.org/publicdomain/zero/1.0/) applies to the data made available in this article, unless otherwise stated. 


\section{Background}

Preeclampsia is defined as hypertension accompanied by proteinuria first detected after 20 weeks of gestation with or without generalized edema $[1,2]$. It has remained a significant public health threat in both developed and developing countries, and contributes to maternal and perinatal morbidity and mortality globally [3, 4]. Preeclampsia has shown an increasing trend in Ethiopia with an estimated prevalence of $8.4 \%$, and ranks third among the top four causes of maternal mortality in the country [5-7].

Preeclampsia is characterized by metabolic disturbances similar to those found in cardiovascular diseases and type 2 diabetes mellitus (T2DM), including endothelial dysfunction, inflammation, oxidative stress, insulin resistance and dyslipidemia [8]. A multisystem nature of the syndrome with involvement of almost all organs, activation of coagulation and increased sensitivity to pressor agents have led to extensive research and understanding of the disorder in recent years $[9,10]$. However, definite causes of preeclampsia have not yet been discovered.

Although the etiology of preeclampsia remains largely unclear, evidence suggests that several factors, including, but not limited to, age, body size and maternal diet play a role in the etiology of preeclampsia $[8,11]$. There is compelling evidence that obesity increases the risk of preeclampsia about 3-folds, and is the leading risk factor in developed countries [12].

On the other hand, a healthy diet characterized by high intake of calcium, vegetables, fruits and vegetable oils was associated with reduced risk of preeclampsia in women [13-15]. Observational studies revealed that dietary components and qualities associated with macronutrients, micronutrients, dietary fiber, alcohol, caffeine, individual foods as well as overall food patterns have links with occurrence of preeclampsia [16-18]. Trials aimed at preeclampsia prevention, however, yielded diverse and often inconsistent results across studies $[12,19,20]$.

Therefore, this study has aimed to explore the effect of obesity and dietary factors on early onset, late onset and overall preeclampsia in order to better understand the risk and protective factors of preeclampsia in the region.

\section{Methods}

\section{Study design and period}

A facility-based unmatched case- control study was conducted on pregnant women, attending antenatal care or skilled delivery in Bahir Dar City, Ethiopia, from June to September, 2014.

\section{Study area}

Bahir Dar is the capital city of Amhara region; the second largest and populous region in the country located approximately $565 \mathrm{~km}$ northwest of the capital city, Addis Ababa.
The city has one public referral hospital, two private hospitals, 6 public health centers, and about 12 higher and medium private clinics. These facilities serve approximately 5 million people in the city and the neighboring districts. All of these facilities provide ANC and skilled delivery services. The study involved only public health facilities (a referral hospital and 6 health centers) because the characteristics of women visiting these facilities were similar and the higher proportions (98\%) of the cases were identified from them. Currently, utilization of Antenatal Care (ANC) and skilled delivery services in the region is 43 and $10.2 \%$ respectively. Only $1 / 5^{\text {th }}$ of women who had ANC visits attend skilled delivery service [7]. The characteristics of women who attend ANC or skilled delivery service are similar with no variation in the type of health facility (hospital or health center) they visit to receive either of the services.

\section{Study population}

Pregnant women who began attending Antenatal Care (ANC) or those who were seeking skilled delivery service during the study period were enrolled in the study. Except in case of the outcome of interest, cases and controls had similar background characteristics. The proportion of ANC attendance was equal for the cases and controls (96\% vs 95.4\%). However, complete data on the number of ANC visits in reference to controls were not obtained. There was no difference in background information between participants and nonparticipants.

A case refers to pregnant women who were diagnosed to have any form of preeclampsia/eclampsia during ANC follow up or delivery by a clinician (doctor, midwife or trained nurse). Preeclamptic women were identified as cases if they experience blood pressure of 140/ $90 \mathrm{mmHg}$ or higher at least twice $4 \mathrm{~h}$ apart after 20 weeks of pregnancy, as well as urine laboratory result revealing protein excretion [21].

Controls are normotensive women who already delivered during the same time as cases. As soon as a case was identified, two controls were enrolled by random sampling method from the same health facility. To avoid misclassification of potential cases as controls, a 48-h post-partum waiting time was required.

Sample size was determined using EPI info stat calculator for two populations, taking $85 \%$ power of the test, $95 \%$ confidence level and a case to control ratio of 1: 2 . The sample size was determined to detect an odds ratio of 2.3. This estimation was taken from a previous study that identified advanced age as a risk factor for preeclampsia [11]. Based on the assumption, the total sample size required for cases and controls, including a $10 \%$ non-response was 151 and 302 respectively. 


\section{Sampling technique and procedure}

Proportional allocation of sample size was made to the participating institutions. Pregnant women who were attending ANC or delivery service during the study period and fulfilled the inclusion criteria were recruited until the allotted sample was reached. Survivor sampling method was employed to enroll the study participants. Cases were enrolled until the required sample size was obtained. For each case, two controls (women who already delivered) were selected by using a simple random sampling technique from the same health facility on the same day.

\section{Study variables}

The presence of preeclampsia/eclampsia during pregnancy or delivery was the outcome variable, whereas maternal socio-demographic characteristics (age, marital status, education, residence, monthly income in Birr $(1 \$=20$ Birr $)$ and maternal occupation), dietary habits (intake of fruit, green vegetables, meat and animal product, and folate) prior to and/or during pregnancy, nutritional status (Mid-Upper Arm Circumference (MUAC) and Hemoglobin value (Hgb) measured in the first trimester) and maternal lifestyle patterns (physical exercise, alcohol intake and coffee consumption) were the independent variables.

Based on Gestational Age (GA), preeclampsia was classified as early onset $(<34$ completed weeks gestation), late onset ( $\geq 34$ completed weeks gestation) and overall preeclampsia [11].

\section{Context}

Ethiopia is one of the poorest countries in the world where approximately $30 \%$ of its population live below the poverty line (income per capita $<\$ 1.25$ ). Eighty four percent of its people live in rural areas, mostly with rainfall dependent subsistent farming as a means of survival [22].

The staple diet for most (98\%) of the study population is Enjera (a pancake-like thin and enormous bread baked from Teff-a local cereal, wheat or maize flour) and a stew/sauce prepared from a cooked mix of milled legumes, onions and oil, taken on an average of two times per day. Despite being advised by care providers, regular intake of green vegetables, fruit and optimum amount of animal products is unaffordable to most of the population, including pregnant women despite being advised by care providers to do so.

Iron and folic acid supplement in the form of folate is universally given to all pregnant women during ANC follow up. Self-reported compliance to folate supplement varies between 70 and $86 \%$ in the region. In our study, compliance to folate intake was determined if a woman has been taking folate tablets daily as per the WHO recommendation [23].
Intake of fruits, vegetables and animal products was considered adequate if a woman has been taking fruit, vegetables and one of the animal products at least 3 times per week 6 months prior to the detection of the pregnancy.

\section{Measurement of nutritional status}

BMI and MUAC are often used to classify pregnant women as underweight, normal, overweight or obese by measuring nutritional status and body size The use of BMI at about 10 weeks of gestation to assess nutritional status in adults, including pregnant women has been recommended in developing countries [24]. However, pregnant women in the study area did not book early antenatal care; therefore, their actual weights at 10 weeks of gestation were not available. Thus, MUAC was used to assess body size, as it was considered to be stable during pregnancy [25]. Based on literatures classification $[25,26]$, we classified MUAC value as underweight $(<23 \mathrm{~cm})$, normal $(23-24.9 \mathrm{~cm})$ and obese (25 more).

\section{Data collection procedure}

Interviewer-administered pre-tested questionnaire was used to collect the data. MUAC was measured at the time of interviews and maternal medical charts were reviewed to collect information on hemoglobin.

\section{Data analysis}

Data were coded, cleaned and entered into SPSS version 20. Frequencies were run to check for accuracy, outliers, inconsistencies and missed values and variables. Then, the data were exported to STATA version 12 for analysis. Univariate logistic regression analysis was employed for the initial inspection of the associations between the outcome and independent variables. Confidence intervals, at the $95 \%$ level were reported for each unadjusted and adjusted OR.

The analyses were repeated in order to determine association of risk factors in early and late onset of preeclampsia [11]. There was no collinearity between explanatory variables as the Mean Variance Inflation Factor (MVIF) was 1.3 and the variance inflation factor for each individual variable was less than 2 .

Multivariate logistic regression analyses were employed to control for confounding and stratified analysis were performed to evaluate effect measure modification by age. In looking at the putative association between MUAC and preeclampsia, maternal age, residence, marital status, occupation and monthly income were anticipated as potential confounders. Hence all the covariates were entered into the multivariate logistic regression model.

Age was found to be an effect modifier; thus it was evaluated through stratification into broad age groups and several stratum specific homogenous categories. The 
results were compared among different categories of age for three forms of preeclampsia. Finally, a separate age stratified and adjusted analysis of the covariates was conducted and the result of this analysis is discussed in detail.

\section{Results}

Socio-demographic characteristics of study participants A total of 453, (151 cases and 302 controls) pregnant women who came for antenatal follow up or skilled delivery services were enrolled in this study. The aggregated mean age of the study participants was 27.14 years ( $28.14 \pm 6.3$ for cases and $26.63 \pm 5.4$ for controls), ranging between 16 and 43 years. Relatively higher proportions of cases than controls were older, uneducated and urban residents (Table 1).

\section{Maternal body size and dietary characteristics}

Among participants, higher proportion (49\%) of the cases had a higher MUAC $(\geq 25 \mathrm{~cm})$ measure than controls (35\%). Furthermore, higher proportions of cases $(82.1 \%)$ were reported to have consumed coffee daily than controls $(65.6 \%)$. Significantly more proportions of controls were reported to have taken fruits, vegetables and folates during pregnancy than cases (Table 1). The majority of cases (96\%) and controls (95.4 \%) had ANC attendance during their last pregnancy.

The effect of maternal socio-demographic characteristics, body size and dietary habits on preeclampsia

The Univariate analysis in this study revealed several factors that are associated with overall preeclampsia. Illiteracy $(\mathrm{COR}=2.18,95 \% \mathrm{CI}: 1.19,4.62)$, rural residence $(\mathrm{COR}=1.53,95 \% \mathrm{CI}: 1.03,2.28)$, anemia $(\mathrm{COR}=3.96,95 \% \mathrm{CI}: 1.12,2.46)$, intake of vegetables $(\mathrm{COR}=0.31,95 \% \mathrm{CI}: 0.12,0.50)$ and $/$ or meat/animal product (COR $=1.34,95 \% \mathrm{CI}: 1.06,2.28)$ were the covariates that were significantly associated with overall preeclampsia in the Univariate model (Tables 1 and 2). However, these factors turned out to be insignificant in the multivariate logistic regression model (Table 3).

Similar results were observed when socio-demographic characteristics, body size and dietary habits were analyzed with late onset preeclampsia. Advanced maternal age $(\mathrm{COR}=1.77,95 \% \mathrm{CI}: 1.00,3.26)$, rural residence $(\mathrm{COR}=$ $1.56,95 \% \mathrm{CI}: 1.00,2.45)$, vegetable consumption $(\mathrm{COR}=$ $0.35,95 \%$ CI: $0.20,0.61$ ) and daily consumption of coffee $(\mathrm{COR}=1.97,95 \% \mathrm{CI}: 1.12,3.22)$ were the covariates significantly associated with late onset preeclampsia in the Univariate model; however, none of these covariate retain

Table 1 Socio-demographic characteristics of women attending ANC and/or skilled delivery service in Bahir Dar City, October 2014

\begin{tabular}{|c|c|c|c|c|c|c|c|}
\hline \multirow{3}{*}{$\begin{array}{l}\text { Variables } \\
\text { Individual factors }\end{array}$} & \multicolumn{2}{|c|}{ Preeclampsia } & \multicolumn{5}{|l|}{ \#COR $(95 \%$ Cl) } \\
\hline & \multirow[t]{2}{*}{ Cases \# (\%) } & \multirow[t]{2}{*}{ Controls \# (\%) } & \multirow[t]{2}{*}{$\begin{array}{l}\text { Preeclampsia } \\
\text { All cases }\end{array}$} & \multicolumn{2}{|c|}{ Early onset Preeclampsia } & \multicolumn{2}{|c|}{ Late onset Preeclampsia } \\
\hline & & & & & & & \\
\hline \multicolumn{8}{|l|}{ Age } \\
\hline$<35$ years & $123(82)$ & $268(88.7)$ & Base & 39 & Base & 84 & Base \\
\hline$>=35$ years & $28(18.0)$ & $34(11.3)$ & $2.04(1.02,4.07)$ & 9 & $1.18(0.92,1.52)$ & 19 & $1.77(0.99,3.26)$ \\
\hline \multicolumn{8}{|l|}{ Residence } \\
\hline Urban & $82(54.3)$ & $195(64.6)$ & Base & 26 & Base & 56 & Base \\
\hline Rural & $69(45.7)$ & $107(35.4)$ & $1.53(1.03,2.28)$ & 22 & $1.54(0.83,2.85)$ & 47 & $1.56(0.99,2.45)$ \\
\hline \multicolumn{8}{|l|}{ Marital status } \\
\hline Married & $141(93.4)$ & $281(93.0)$ & Base & 45 & & 96 & Base \\
\hline Single $e^{a}$ & $10(6.6)$ & $21(7.0)$ & $0.95(0.43,2.06)$ & 3 & $1.03(0.42,2.49)$ & 7 & $1.00(0.40,2.35)$ \\
\hline \multicolumn{8}{|l|}{ Occupation } \\
\hline Employed & $33(21.8)$ & $72(23.8)$ & Base & 12 & & 21 & Base \\
\hline Merchant & $25(16.6)$ & $44(14.6)$ & $1.21(0.65,2.35)$ & 8 & $1.09(0.41,2.88)$ & 17 & $1.33(0.63,2.78)$ \\
\hline House wife & $93(61.6)$ & $186(61.6)$ & $1.17(0.54,2.54)$ & 28 & $0.90(0.43,1.87)$ & 65 & $1.21(0.69,2.13)$ \\
\hline \multicolumn{8}{|l|}{ Education } \\
\hline Unable to read \& write & $70(40.9)$ & $68(24.1)$ & $2.18(1.19,4.62)$ & 27 & $1.11(0.701 .73)$ & 44 & $1.12(0.71,1.76)$ \\
\hline Able to read \& write & $101(59.1)$ & $214(75.9)$ & Base & 21 & Base & 59 & Base \\
\hline \multicolumn{8}{|l|}{ Monthly Income } \\
\hline$<1500$ Birr & $88(58.3)$ & $170(56.3)$ & $0.92(0.62,1.37)$ & 28 & $0.92(0.49,1.70)$ & 60 & $1.09(0.70,1.73)$ \\
\hline$>1500$ Birr & $63(41.7)$ & $132(43.7)$ & Base & 20 & Base & 43 & Base \\
\hline
\end{tabular}


Table 2 Univariate analysis of nutritional, dietary and lifestyle factors with incidence of preeclampsia, Bahir Dar City, October, 2014

\begin{tabular}{|c|c|c|c|c|c|c|c|}
\hline \multirow[t]{2}{*}{ Variables } & \multicolumn{2}{|c|}{ Preeclampsia } & \multicolumn{5}{|l|}{ \#COR (95\% Cl) } \\
\hline & Yes \# (\%) & No \# (\%) & Overall preeclampsia & \multicolumn{2}{|c|}{ Early Pre-eclampsia } & \multicolumn{2}{|c|}{ Late onset Preeclampsia } \\
\hline \multicolumn{8}{|c|}{ Nutritional, dietary and lifestyle factors } \\
\hline \multicolumn{8}{|l|}{ MUAC } \\
\hline$<23 \mathrm{~cm}$ & $41(27.2)$ & $115(38.0)$ & Base & 16 & Base & 25 & Base \\
\hline $23-24.9 \mathrm{~cm}$ & $36(23.8)$ & $82(27.2)$ & $1.23(0.72,2.09)$ & 13 & $1.14(0.52,2.49)$ & 23 & $1.27(0.67,2.39)$ \\
\hline $25 \mathrm{~cm}$ and above & $74(49.0)$ & $105(34.8)$ & $1.98(1.24,3.14)$ & 19 & $1.30(0.63,2.66)$ & 55 & $2.67(1.38,4.07)$ \\
\hline \multicolumn{8}{|l|}{ Fruit intake } \\
\hline Yes & $92(60.9)$ & $247(81.8)$ & $0.35(0.22,0.54)$ & 21 & $0.29(0.15,0.54)$ & 38 & $0.37(0.22,0.60)$ \\
\hline No & $59(39.1)$ & $55(18.2)$ & Base & 27 & Base & 65 & Base \\
\hline \multicolumn{8}{|l|}{ Vegetable intake } \\
\hline Yes & $105(69.5)$ & $266(88.0)$ & $0.31(0.12,0.50)$ & 31 & $0.35(0.19,0.60)$ & 74 & $0.35(0.20,0.61)$ \\
\hline No & $46(30.5)$ & $36(12.0)$ & Base & 17 & Base & 29 & Base \\
\hline \multicolumn{8}{|c|}{ Meat/animal product intake } \\
\hline Yes & $143(94.7)$ & $281(93.0)$ & $1.34(1.06,2.28)$ & 44 & $1.22(0.39,3.71)$ & 99 & $1.86(0.62,5.56)$ \\
\hline No & $8(5.3)$ & $21(7.0)$ & Base & 4 & Base & 4 & Base \\
\hline \multicolumn{8}{|l|}{ Coffee intake } \\
\hline Yes & $124(82.1)$ & $198(65.6)$ & $2.41(1.49,3.90)$ & 43 & $4.51(1.73,11.75)$ & 81 & $1.97(1.12,3.22)$ \\
\hline No & $27(17.9)$ & $104(34.4)$ & Base & 5 & Base & 22 & Base \\
\hline \multicolumn{8}{|l|}{ Folate intake } \\
\hline Yes & 99 (65.6) & $283(93.7)$ & $0.13(0.07,0.23)$ & 31 & $0.12(0.06,0.26)$ & 68 & $0.13(0.07,0.24)$ \\
\hline No & $52(34.4)$ & $19(6.3)$ & Base & 17 & Base & 35 & Base \\
\hline \multicolumn{8}{|l|}{ Anemia $(n=323)$} \\
\hline Yes & $18(14.9)$ & $10(4.9)$ & $3.96(1.54,10.17)$ & 5 & $1.11(0.13,9.27)$ & 13 & $5.52(2.11,14.44)$ \\
\hline No & $103(85.1)$ & $192(95.1)$ & Base & 47 & Base & 38 & \\
\hline \multicolumn{8}{|l|}{ Alcohol intake } \\
\hline Yes & $80(53.0)$ & $122(40.4)$ & $1.66(1.12,2.46)$ & 26 & $1.63(1.04,2.55)$ & 54 & $1.61(1.03,2.52)$ \\
\hline No & $71(47.0)$ & 180 (59.6) & Base & 22 & Base & 49 & Base \\
\hline \multicolumn{8}{|l|}{ Physical exercise } \\
\hline Yes & $118(78.1)$ & $254(84.1)$ & $0.68(0.42,1.11)$ & 40 & $0.59(0.32,1.12)$ & 78 & $0.64(0.34,1.03)$ \\
\hline No & 33 (21.9) & 48 (15.9) & Base & 8 & Base & 25 & Base \\
\hline
\end{tabular}

their significance in the adjusted model (Table 2). On the other hand, vegetable intake $(\mathrm{COR}=0.35,95 \% \mathrm{CI}: 0.19$, $0.60)$ and alcohol consumption $(\mathrm{COR}=1.63,95 \% \mathrm{CI}: 1.04$, $2.55)$ were also associated with early onset preeclampsia.

Since the association of preeclampsia with dietary pattern may be related with other covariates, variables which had statistical significance in the Univariate logistic regression model were entered into the multivariate logistic regression model separately for overall and late onset preeclampsia.

After controlling for confounding factors, including residence, education, anemia, alcohol intake and consumption of meat, five covariates remain significantly associated with overall preeclampsia.

The likelihood of overall preeclampsia was evident for women who had a higher MUAC measure. Obese women (MUAC $\geq 25 \mathrm{~cm}$ ) were three times more likely than their normal (MUAC 23-24.99 cm) and underweight (MUAC $<23 \mathrm{~cm}$ ) counterparts to have overall preeclampsia $(\mathrm{AOR}=3.33,95 \% \mathrm{CI}: 1.87,5.79)$. The odds of overall preeclampsia were higher among advanced age women $(\mathrm{AOR}=2.07,95 \% \mathrm{CI}$ : 1.02, 4.19). Women who reported to have taken coffee daily were two times more likely to develop preeclampsia than who did not $(\mathrm{AOR}=2.14,95 \% \mathrm{CI}: 1.32,3.46)$. The likelihood of overall preeclampsia was prevented by 53 and $82 \%$ among women reported to have compliant to folate supplement $(\mathrm{AOR}=0.47,95 \% \mathrm{CI}: 0.27,0.83)$ and among women reported to have adequate fruit intake prior to or during pregnancy $(\mathrm{AOR}=0.18,95 \% \mathrm{CI}$ : 0.10, 0.32) (Table 3).

Except for advanced maternal age and coffee consumption, obesity (AOR = 3.63, $95 \% \mathrm{CI}: 1.89,6.97)$, fruit intake ( $\mathrm{AOR}=0.34,95 \% \mathrm{CI}: 0.16,0.71)$ and compliance 
Table 3 Result of multivariate logistic regression analysis of covariates with early onset, late onset and overall incidence of preeclampsia, Bahir Dar City, October, 2014

\begin{tabular}{|c|c|c|c|}
\hline \multirow[t]{3}{*}{ Covariates } & All Preeclampsia & Early Onset Preeclampsia & Late Onset Preeclampsia \\
\hline & $(n=151)$ & $(n=48)$ & $(n=103)$ \\
\hline & Adjusted OR (95 \% Cl), & Adjusted OR (95 \% Cl), & Adjusted OR (95 \% Cl), \\
\hline \multicolumn{4}{|l|}{ Age } \\
\hline$<35$ years & Base $^{a}$ & Base & Base \\
\hline$>=35$ years & $2.07(1.02,4.19)$ & $1.27(0.48,3.38)$ & $1.56(0.74,3.24)$ \\
\hline \multicolumn{4}{|l|}{ Marital status } \\
\hline Married & Base & & Base \\
\hline Rural & $1.43(0.78,2.68)$ & $1.27(0.49,3.28)$ & $1.13(0.60,2.11)$ \\
\hline \multicolumn{4}{|l|}{ MUAC } \\
\hline$<23 \mathrm{~cm}$ & Base & Base & Base \\
\hline $23-24.9 \mathrm{~cm}$ & $1.63(0.84,2.85)$ & $1.37(0.54,3.48)$ & $1.24(0.69,2.56)$ \\
\hline $25 \mathrm{~cm}$ and above & $3.33(1.87,5.79)^{*}$ & $1.98(0.79,4.94)$ & $3.63(1.89,6.97)^{*}$ \\
\hline \multicolumn{4}{|l|}{ Fruit intake } \\
\hline Yes & $0.47(0.27,0.83)^{*}$ & $0.32(0.11,0.96)$ & $0.34(0.16,0.71)^{*}$ \\
\hline No & Base & Base & Base \\
\hline \multicolumn{4}{|l|}{ Vegetable intake } \\
\hline Yes & $0.59(0.30,1.15)$ & $0.48(0.17,1.35)$ & $0.21(0.90,3.71)$ \\
\hline No & Base & Base & Base \\
\hline \multicolumn{4}{|l|}{ Coffee intake } \\
\hline Yes & $2.14(1.32,3.46)^{*}$ & $2.36(0.84,6.62)$ & $1.53(0.84,2.83)$ \\
\hline No & Base & Base & Base \\
\hline \multicolumn{4}{|l|}{ Folate intake } \\
\hline Yes & $0.18(0.10,0.32)^{*}$ & $0.12(0.04,0.33)^{*}$ & $0.16(0.08,0.33)^{*}$ \\
\hline No & Base & Base & Base \\
\hline \multicolumn{4}{|l|}{ Anemia $(n=323)$} \\
\hline Yes & $1.89(0.64,5.61)$ & $1.19(0.11,12.82)$ & $2.97(0.91,9.69)$ \\
\hline No & Base & Base & Base \\
\hline \multicolumn{4}{|l|}{ Alcohol intake } \\
\hline Yes & $1.31(0.79,2.18)$ & $1.21(0.56,2.62)$ & $0.69(0.39,1.20)$ \\
\hline No & Base & Base & Base \\
\hline \multicolumn{4}{|c|}{ Meat/animal product intake } \\
\hline Yes & $1.53(0.56,4.20)$ & $1.00(0.25,4.07)$ & $3.07(0.51,18 . .66)$ \\
\hline No & Base & Base & Base \\
\hline \multicolumn{4}{|l|}{ Physical exercise } \\
\hline Yes & $0.28(0.02,2.99)$ & $0.85(0.32,2.26)$ & $0.69(0.32,7.00)$ \\
\hline No & Base & Base & Base \\
\hline
\end{tabular}

Adjusted for maternal age, ${ }^{*}$ statistically significant at $P$ value $<0.05$ with $95 \% \mathrm{Cl}$ ${ }^{a}$ Reference category

to folate supplement $(\mathrm{AOR}=0.16,95 \% \mathrm{CI}$ : 0.08, 0.33) have shown odds of similar magnitude with late onset preeclampsia in the multiple logistic regression model.

However, obesity did not show any association with early onset preeclampsia (AOR $=1.30,95 \%$ CI: $0.63,2.66$ ) while fruit consumption and compliance to folate supplement have shown a protective effect against early onset preeclampsia (AOR $=0.32,95 \%$ CI: 0.11, 0.96) and (AOR = $0.12,95 \%$ CI: 0.04, 0.33), respectively (Table 3 ).

Factors such as marital status, monthly income, occupation and physical exercise did not show any significant association with preeclampsia in this study. 


\section{Age stratified analysis of the effect of MUAC on preeclampsia}

Based on the stratified analysis, a confounding effect between MUAC and suspected confounders was not observed. However, age was found to have effect modification with MUAC in its relationship with the overall and late onset preeclampsia. Substantial variation was observed between the stratum specific estimates (ORs) of MUAC when stratified by age. The effect of obesity on overall preeclampsia was significant among women younger than 35 years $(\mathrm{COR}=1.81,95 \% \mathrm{CI}: 1.11,2.99)$ (Table 4$)$.

When age groups were made more homogenous through adjusted stratification, it became evident that obesity was strongly associated with overall preeclampsia among women age $\leq 24$ years $(\mathrm{AOR}=2.31,95 \% \mathrm{CI}: 1.07$, 5.12) and 25-29 years ( $\mathrm{AOR}=3.16,95 \% \mathrm{CI}: 1.21$, 8.24). Odds of similar magnitude were observed in the relationship between obesity and late onset preeclampsia in women age $\leq 24$ years and $25-29$ years $(\mathrm{AOR}=3.66,95 \%$ CI: $1.37,10.87)$ and $(\mathrm{AOR}=1.98,95 \% \mathrm{CI}: 1.16,3.40)$, respectively (Table 5).

With regard to age stratified adjusted relationship between folate intake and preeclampsia, fruit intake and compliance to folate supplement during pregnancy have shown a consistent protective effect against overall and late onset preeclampsia across almost all age groups. The odds of developing preeclampsia was 70 and $75 \%$ lower among women who used fruit in their diet as compared to non-users for overall and late onset preeclampsia respectively.

The odds of developing overall and late onset preeclampsia was 70 and $75 \%$ lower among women who used fruits in their diet as compared to non-users.

The age stratified adjusted logistic regression analysis shows a significant predictive association between coffee consumption and overall $(\mathrm{AOR}=4.39,95 \% \mathrm{CI}$ : 1.32, 14.56) and late onset preeclampsia $(\mathrm{AOR}=3.87,95 \%$ CI: $1.31,13.79)$ among young $(\leq 24$ years $)$ women

Table 4 Result of age stratified crude analysis of the effect of MUAC on preeclampsia, Bahir Dar City, October, 2014

\begin{tabular}{|c|c|c|}
\hline Age & COR & [95 \% Conf. Interval] \\
\hline \multicolumn{3}{|c|}{ The effect of MUAC on Overall preeclampsia when stratified by AGE } \\
\hline$<35$ years & 1.81 & $1.11,2.99^{\mathrm{a}}$ \\
\hline$\geq 35$ years & 0.77 & $0.21,2.82$ \\
\hline \multicolumn{3}{|c|}{ The effect of MUAC on Early onset preeclampsia when stratified by } \\
\hline$<35$ years & 1.33 & $0.62,2.94$ \\
\hline$\geq 35$ years & 0.62 & $0.10,4.72$ \\
\hline \multicolumn{3}{|c|}{ The effect of MUAC on Late onset preeclampsia when stratified by AGE } \\
\hline$<35$ years & 2.09 & $1.16,3.86^{\mathrm{a}}$ \\
\hline$\geq 35$ years & 0.86 & $0.20,4.03$ \\
\hline
\end{tabular}

${ }^{a}$ statistically significant at $95 \% \mathrm{Cl}$
(Table 5). However, except compliance to folate supplement among women age 30-34 years, none of the other covariate were found to be significantly associated with early onset preeclampsia in the age adjusted stratified analysis (Table 5).

\section{Discussion}

This case control study aimed at determining the effect of obesity and dietary habits on preeclampsia among women in Ethiopia. We assessed the effect of a wide range of factors on preeclampsia and found that obesity, advanced maternal age and coffee consumptions are risk factors for preeclampsia. On the other hand, fruit and/or vegetable consumption and compliance to folate supplement were protective factors against preeclampsia.

The study revealed a positive relationship in the risk of pre-eclampsia with increasing mid-arm circumference. Obese (MUAC $\geq 25 \mathrm{~cm}$ ) women were three times more likely to develop preeclampsia than women in the normal $(23-24.99 \mathrm{~cm})$ or underweight $(<23 \mathrm{~cm})$ range. The result was consistent with studies that showed obese women are two to three times more likely to develop preeclampsia than their leaner counterparts [11, 12].

The authors checked if the observed relationship between MUAC and preeclampsia was confounded by maternal age or not. The age stratified analysis revealed an effect modification/interaction between MUAC and maternal age. The effect of obesity on overall and late onset preeclampsia was evident only for younger ( $<35$ years) women, mainly for age $\leq 24$ years and 25-29 years. This study discovered that obesity has no association with pre-eclampsia among older women as opposed to what is commonly known. When age increased, body size and risk of preeclampsia also increased as supported by other studies [6, 11, 27]. We speculated that an increase in obesity trend among young women might be a strong risk factor underlying the observed incidence of preeclampsia [28]. The rapid shift in population towards a more obese phenotype in recent years might lead to a marked increase in the incidence of overweight and obese women of childbearing age, including preeclampsia in early ages [12]. The possible variation in the distribution of age between cases and controls and the time at which MUAC was measured might attribute to the attenuation of our results. The use of MUAC is also not a sensitive measure of body size $[25,29]$. Other than chance, our findings may have at least two possible interpretations: obesity is a risk factor for preeclampsia in young age, or our methodological limitations might have created a spurious predictive association. However, this study did not find a causal relationship between obesity and early onset preeclampsia. Large-scale population based studies using BMI instead of MUAC may provide evidence to corroborate or refute the current findings. 
Table 5 Result of age stratified and adjusted analysis of covariates significantly associated with overall, early onset and late onset preeclampsia, Bahir Dar City, October, 2014

\begin{tabular}{|c|c|c|c|c|c|c|}
\hline \multirow[t]{2}{*}{ Covariates } & \multicolumn{2}{|c|}{ Overall Preeclampsia } & \multicolumn{2}{|c|}{ Early onset Preeclampsia } & \multicolumn{2}{|c|}{ Late onset preeclampsia } \\
\hline & $\overline{O R}$ & $95 \% \mathrm{Cl}$ & $\overline{\mathrm{OR}}$ & $95 \% \mathrm{Cl}$ & $\overline{\mathrm{OR}}$ & $95 \% \mathrm{Cl}$ \\
\hline & \multicolumn{6}{|c|}{ Age $\leq 24$ years } \\
\hline MUAC: Normal vs underweight & 1.07 & $0.17,6.67$ & 0.30 & $0.07,1.34$ & 1.53 & $0.71,3.29$ \\
\hline Obese vs underweight & 2.31, & $1.06,5.12^{\mathrm{a}}$ & 1.00 & $0.66,23.93$ & 3.66 & $1.37,10.87^{a}$ \\
\hline Fruit intake: yes vs no & 0.30 & $0.13,0.72^{a}$ & 0.71 & $0.17,3.18$ & 0.25 & $0.09,0.68^{\mathrm{a}}$ \\
\hline Adherence to folate: yes vs no & 0.16 & $0.05,0.46^{a}$ & 0.71 & $0.17,3.18$ & 0.09 & $0.02,0.42^{\mathrm{a}}$ \\
\hline \multirow[t]{2}{*}{ Coffee consumption : yes vs no } & 4.39 & $1.32,14.56^{\mathrm{a}}$ & 0.67 & $0.13,3.34$ & 3.87 & $1.31,13.79^{\mathrm{a}}$ \\
\hline & \multicolumn{6}{|c|}{ Age $25-29$ years } \\
\hline MUAC: Normal vs underweight & 2.21 & $0.58,8.47$ & 5.75 & $0.64,51.57$ & 1.89 & $0.68,5.26$ \\
\hline Obese vs underweight & 3.16 & $1.21,8.24^{\mathrm{a}}$ & 5.16 & $0.55,48.40$ & 1.98 & $1.16,3.40^{\mathrm{a}}$ \\
\hline Fruit intake: yes vs no & 0.74 & $0.26,2.12$ & 0.52 & $0.12,2.33$ & 0.64 & $0.22,1.81$ \\
\hline Adherence to folate: yes vs no & 0.11 & $0.03,0.38^{\mathrm{a}}$ & 0.86 & $0.08,8.54$ & 0.09 & $0.03,0.30^{a}$ \\
\hline \multirow[t]{2}{*}{ Coffee consumption : yes vs no } & 1.24 & $0.51,3.01$ & 0.25 & $0.03,2.09$ & - & - \\
\hline & \multicolumn{6}{|c|}{ Age 30-34 years } \\
\hline MUAC: Normal vs underweight & 1.16 & $0.40,3.35$ & 2.76 & $0.20,36.77$ & 0.64 & $0.42,3.94$ \\
\hline Obese vs underweight & 1.04 & $0.26,4.13$ & 2.86 & $0.26,31.53$ & 0.91 & $0.42,1.97$ \\
\hline Fruit intake: yes vs no & 0.41 & $0.11,1.49$ & 0.04 & $0.03,1.49$ & 0.70 & $0.16,2.97$ \\
\hline Adherence to folate: yes vs no & 0.12 & $0.03,0.47^{\mathrm{a}}$ & 0.03 & $0.02,0.27^{\mathrm{a}}$ & 0.20 & $0.04,0.93^{\mathrm{a}}$ \\
\hline \multirow[t]{2}{*}{ Coffee consumption : yes vs no } & 1.14 & $0.29,4.51$ & 0.50 & $0.04,6.63$ & - & - \\
\hline & \multicolumn{6}{|c|}{ Age $>35$ years } \\
\hline MUAC: Normal vs underweight & 0.38 & $0.06,2.38$ & 0.37 & $0.03,4.06$ & 0.90 & $0.16,5.04$ \\
\hline Obese vs underweight & 3.45 & $0.53,22.54$ & 2.87 & $0.21,39.07$ & 1.57 & $0.62,3.97$ \\
\hline Fruit intake: yes vs no & 0.21 & $0.05,0.94^{\mathrm{a}}$ & 0.15 & $0.01,1.73$ & 0.22 & $0.05,1.05$ \\
\hline Adherence to folate: yes vs no & 0.23 & $0.03,1.54$ & 0.21 & $0.02,1.87$ & 0.13 & $0.02,0.80^{\mathrm{a}}$ \\
\hline Coffee consumption : yes vs no & 3.67 & $0.52,25.69$ & \multicolumn{2}{|c|}{ Omitted } & - & - \\
\hline
\end{tabular}

${ }^{a}$ Statistically significant after controlling for age through adjusted stratification

Measures of body composition, including percent body fat mass, may very likely identify obese women at risk of preeclampsia more accurately [12, 29]. However, our findings are useful in predicting risk of obesity for preeclampsia among young women in the country.

Consistent with other studies [30], this study revealed that daily coffee intake during pregnancy has statistically significant association with the occurrence of overall preeclampsia. Studies in Norway [15, 19] found higher caffeine (coffee or tea) intake during pregnancy is associated with elevated systolic blood pressure levels in first and third trimester pregnancy. The mechanism by which caffeine exposure affects heart rate and blood pressure levels might include increase of catecholamine levels, which may subsequently lead to vasoconstriction. Differences in blood pressure levels associated with caffeine intake during pregnancy might be markers of subclinical cardiovascular adaptation mechanisms and the subsequent risk of hypertensive complications, such as pregnancy-induced hypertension and pre-eclampsia
$[18,31]$. Some studies reported that caffeine intake only increases incidence of systolic hypertension during the first trimester pregnancy, but did not have any effect later or on diastolic blood pressure [32]. However, other studies did not find any evidence on the effects of caffeine intake on blood pressure during pregnancy [31]. In this study, the effect of coffee consumption was apparent only for late onset and overall preeclampsia among younger ( $\leq 24$ years) women. This observation might be due to the sample size and lack of homogeneity of the data distribution between cases and controls. Employing a robust longitudinal design by recruiting a larger sample size may provide credible insight in this regard. Analyzing the amount and frequency of daily caffeine intake, including Coca-Cola and tea may provide more insightful results.

Maternal diet is one of the factors found to play a role in the etiology of pre-eclampsia. In a previous study [19], it was found that high scores on a healthy diet characterized by high intake of vegetables, fruits and 
vegetable oils were associated with reduced risk of preeclampsia in nulliparous women. The findings of this study also revealed that women who eat fruit had a lower risk of developing early onset, late onset and overall preeclampsia than women who did not. This finding is consistent with studies conducted in Norway $[8,13,15,18,19]$ which reported a reduced risk of preeclampsia with organic vegetable consumption. There are several mechanisms for a biological effect of dietary behavior on the incidence of preeclampsia. Fruits are rich in micronutrients such as antioxidants, vitamins, minerals, and dietary fibers. A diet rich in fruits and uncooked vegetables decreased the risk of hyperhomocysteinemia, which is one of the risk factors for the occurrence of preeclampsia [33]. However, the protective effect of fruit consumption in the adjusted stratified analysis was apparent only for some age groups (age $<20$ years and $\geq 35$ years). The mechanism of why fruit consumption has an effect on preeclampsia primarily among very young and older women is not well understood and needs further study. This finding might be due to the variation in the distribution of samples and other unforeseen methodological issues. Intake of vegetable also has a non-significant but an important protective effect against all forms of preeclampsia. In contrast, other previous studies did not find supporting evidence that self-reported intake of organic fruits and vegetables prevent preeclampsia $[20,34]$. Therefore, the researchers in this study believe that the effect of dietary components, including macronutrients, micronutrients, dietary fiber and individual foods as well as overall food patterns and qualities must be assessed using large-scale longitudinal observational studies.

Consistent with previous studies [35, 36], we found that compliance to folate supplementation during pregnancy was associated with a reduced risk of all forms preeclampsia. It was interesting that compliance to folate supplement has shown a protective effect against all forms of preeclampsia across all age categories. Folate supplementation during pregnancy decreases plasma homocysteine concentrations and improves endothelial function in adults with hyperhomocysteinemia [36, 37]. Homocysteine is an amino acid released as the body digests dietary protein. It has been shown that its level increases during preeclampsia and elderly. Too much homocysteine in the blood is linked with a greater risk of heart disease, stroke and nerve damage [8]. Excessive homocysteine in pregnancy might damage the vascular endothelium of the developing placenta by promoting oxidative stress, thereby increasing contractile response and the production of procoagulants and vasoconstrictors which lead to the development of preeclampsia [33]. These findings underscore the need for continued promotion of universal provision of folate for all pregnant women. However, research findings on the effect of folate during pregnancy are controversial. Some studies revealed that taking folate would lead to childhood asthma [38] and reduced fetal growth [39], whereas others did not find any relationship [20]. A prospective observational cohort study may provide more robust evidence.

Unlike other studies [6], maternal education, occupation and residence did not show a significant association with preeclampsia in the current study. Such difference could be due to the variation in study design, sample size and study settings. The effect of anemia and intake of meat and animal product did not turn out significant in the final models either. Residual confounding due to insufficient information or unmeasured lifestyle habits might be involved. Therefore, further research using large sample and validated questionnaires is needed.

Numerous researches have shown that there is no one best way to prevent preeclampsia, though for many years body size and diet have been claimed to play a role in preeclampsia [12, 15]. Increase in the amount of fruits and vegetables and decreasing the amount of fried foods and junk foods, getting enough rest, exercising regularly, avoiding alcohol, avoiding beverages containing caffeine, and taking folate and iron regularly has been recommended by various studies $[12,18,19,34,40]$. The result of this study also supports the above recommendations, including the need to emphasize on prevention of obesity in young women.

The findings of this study should be viewed in light of the following limitations: the use of survivor sampling method to recruit controls might introduce selection bias which leads to heterogeneous distribution of some covariates between cases and controls. As a result, it was impossible to make a comparison between early and late onset preeclampsia. Measurement of MUAC was made at the time of data collection and the effect of pregnancy on body size was not considered. Therefore, the MUAC measurement may not necessarily indicate the pre-conception value. In case-control studies, recall bias and lack of temporal relationship are inherent limitations. The relatively small number of our sample might dilute the potential true effect of some covariates. Hence, generalization of the findings in this study may not be possible.

\section{Conclusions}

Obesity in young age is a risk factor for late onset and overall preeclampsia while compliance to folate supplement and adequate fruit consumption are protective factors. The associated risk and protective factors identified in this study are modifiable. Lifestyle modifications, including weight reduction, before, during and after pregnancy are recommended to reduce the risk of preeclampsia among young women. Universal provision 
and compliance to folate supplement and fruit consumption should always be promoted for pregnant women. Robust research with larger sample size and well-designed methodology needs to be conducted to corroborate our findings.

\section{Acknowledgment}

The authors would like to thank the Rift Valley University for sponsoring this study. The authors are also grateful to thank the Amhara regional health bureau, Bahir Dar city administration health department and health facilities for facilitating the data collection process. We also extend our appreciations to study participants and data collectors for their keen participation. Last, but not least, we thank Muna Ahmed, Yenew Berhan, Tigest Mekonnen and Merykokeb Belay for their technical assistance in proofreading the language.

\section{Funding}

The source of funding for this research was Rift Valley University, Bahir Dar Campus. The funding body had no any involvement in the design of the study, data collection, analysis, and interpretation of data and in writing the manuscript.

\section{Availability of data and materials}

The data used for analysis could be made available up on request.

\section{Authors' contributions}

ME has contributed in the design, data collection and write up of the study protocol, FA has contributed in the design, data analysis, manuscript development and revisions, SW has contributed in the revision and write up of the manuscript, LM has contributed in data analysis and revision of the manuscript, and MA and MA have participated in the revision of the manuscript. All the authors have read and approved the final manuscript.

\section{Competing interests}

The authors declare that they have no competing interests.

\section{Consent for publication}

Not applicable.

\section{Ethics approval and consent to participate}

Ethical clearance was sought from Bahir Dar University, School of Public Health Ethical Review Board. All the study participants were informed about the purpose of the study, their right to refuse or withdraw at any time during the interview and the confidentiality of their information. Then, verbal consent was obtained from each study participant. In addition, strict confidentiality was assured through the anonymous recording of the data and by assigning codes of the questionnaires.

\section{Author details}

${ }^{1}$ Pre-service Education of Health Professionals, International Non-Governmental Organization, P.O. Box, 1566, Bahir Dar, Ethiopia. ${ }^{2}$ Rift Valley University, Bahir Dar Campus, Bahir Dar, Ethiopia. ${ }^{3}$ Medical Education \& In-service Training of Health professionals, ICAP, Addis Ababa, Ethiopia. ${ }^{4}$ Pre-service Education of Health Professionals, Non- Governmental Organization, Bahir Dar, Ethiopia. ${ }^{5}$ Consortium of Christian Relief \& Development Associations (CCRDA), Addis Ababa, Ethiopia. ${ }^{6}$ Bahir Dar Health Science College, Bahir Dar, Ethiopia.

Received: 5 November 2014 Accepted: 15 August 2016 Published online: 19 August 2016

\section{References}

1. Sidani M, SIddik-Sayyid MS. Preclampsia, a new perspective. Mej Anesth. 2011;21(2).

2. WHO. WHO Recommendations for Prevention and Treatment of Preeclampsia and Eclampsia. Geneva: WHO; 2011. Contract No.: Document Number|.

3. Roccella EJ. Bethesda, Maryland. Report of the National High Blood Pressure Education Program Working Group on High Blood Pressure in Pregnancy. Am J Obstet Gynecol. 2000;183:1.

4. WHO. Recommendations for Prevention and Treatment of Preeclampsia and Eclampsia. Department of Maternal and Child Health; 2011.
5. Berhan Y, Berhan A. Causes of maternal mortality in Ethiopia: a significant decline in abortion related death. Ethiop J Health Sci. 2014;24:15-28.

6. Tessema GA, Tekeste A, Ayele TA. Preeclampsia and associated factors among pregnant women attending antenatal care in Dessie referral hospital, Northeast Ethiopia: a hospital-based study. BMC Pregnancy Childbirth. 2015;15(73).

7. CSA. Ethiopia Mini Demographic and Health Survey 2014. 2014.

8. Meltzer HM, Brantsæter AL, Nilsen RM, Magnus P, Alexander J, Haugen M. Effect of dietary factors in pregnancy on risk of pregnancy complications: results from the Norwegian Mother and Child Cohort Study. Am J Clin Nutr. 2011;94(suppl):1970S-4.

9. Sibai B, Dekker G, Baumert M. Pre-eclampsia. Lancet. 2005;365(9461):785-99.

10. Qiu C, Williams MA, Leisenring WM, Sorensen TK, Frederick IO, Dempsey JC, et al. Family history of hypertension and type 2 diabetes in relation to preeclampsia risk. Am Heart Assoc. 2003;41:408-13.

11. Fanga R, Dawsona A, Lohsoonthorna V, Williamsa MA. Risk factors of early and late onset preeclampsia among Thai women. Asian Biomed. 2009;3(5): $477-86$.

12. Itoh H, Naohiro K. Obesity and risk of preeclampsia. Med J Obstet Gynecol. 2014;2(2):1024.

13. Brantsæter AL, Margaretha H, Samuelsen SO, Torjusen H, Trogstad L, Alexander J, et al. A dietary pattern characterized by high intake of vegetables, fruits, and vegetable oils is associated with reduced risk of preeclampsia in nulliparous pregnant Norwegian women. J Nutr. 2009;109: 104968.

14. Cynthia V, Max W. Relationship of twin zygosity and risk of preeclampsia. Am J Obstet Gynecol. 2001;185(4):819-21.

15. Torjusen $H$, Lieblein $G$, Næs $T$, Haugen M, Meltzer HM, Brantsæter AL. Food patterns and dietary quality associated with organic food consumption during pregnancy; data from a large cohort of pregnant women in Norway. BMC Public Health. 2012;12:612.

16. ShiWuWen, Josee Champagne, Ruth Rennicks White, Doug Coyle, William Fraser GS, Dean Fergusson, and Mark C. Walker. Effect of Folic Acid Supplementation in Pregnancy on Preeclampsia: The Folic Acid Clinical Trial Study. J Pregnancy. 2013;294312.

17. Perni UC, Wikström A-K, Cnattingius S, Villamor E. Interpregnancy change in smoking habits and risk of preeclampsia: a population-based study. Am J Hypertens. 2012;25(3):372.

18. Schoenaker DA, Soedamah-Muthu SS, Mishra GD. The association between dietary factors and gestational hypertension and pre-eclampsia: a systematic review and meta-analysis of observational studies. BMC Med. 2014;12:157.

19. Torjusen H, Brantsæter AL, Haugen M, Alexander J, Bakketeig LS, Lieblein G, et al. Reduced risk of pre-eclampsia with organic vegetable consumption: results from the prospective Norwegian Mother and Child Cohort Study. BMJ. 2014;:4:e006143.

20. Morris CD, Jacobson SL, Anand R, Ewell MG, Hauth JC, Curet LB, et al. Nutrient intake and hypertensive disorders of pregnancy: evidence from a large prospective cohort. Am J Obstet Gynecol. 2001;184(4):643-51.

21. Eiland E, Nzerue C, Faulkner M. Preeclampsia 2012. J Pregnancy. 2012;2012:7.

22. World Bank. Economic Overview. The world bank, IBRDIDA. 2015.

23. WHO. Guideline: Daily iron and folic acid supplementation in pregnant women. World Health Organization; 2012

24. Ververs M-t, Antierens A, Sackl A, Staderini N, Captier V. Which anthropometric indicators identify a pregnant woman as acutely malnourished and predict adverse birth outcomes in the humanitarian context? PLoS One. 2013.

25. Mahomed K, Williams MA WG, Jenkins-Woelk L, Mudzamiri S, Longstaff L, Sorensen TK. Risk factors for pre-eclampsia among Zimbabwean women: maternal arm circumference and other anthropometric measures of obesity. Paediatr Perinat Epidemiol. 1998;12(3):253-62.

26. Mulualem Endeshaw FA, Melkamu B, Anemaw A. Diet and pre-eclampsia: a prospective multicentre case-control study in Ethiopia. Midwifery. 2015;31: $617-24$

27. Silva DAS, Petroski EL, Peres MA. Is high body fat estimated by body mass index and waist circumference a predictor of hypertension in adults? A population-based study. Nutr J. 2012;11:112

28. Aliyu MH, Luke S, Kristensen S, Alio AP, Salihu HM. Joint effect of obesity and teenage pregnancy on the risk of preeclampsia: a population-based study. J Adolesc Health. 2010;46(2010):77-82.

29. Derbyshire E. Can anthropometric and body composition measurements during pregnancy be used to predict preeclampsia risk? Curr Womens Health Rev. 2009;5:225-9. 
30. Spaans F, Pd V, Bakker WW, Hv G, Faas MM. Danger signals from ATP and adenosine in pregnancy and preeclampsia. Am Heart Assoc. 2014;63:1154-60.

31. Sharbaf FR, Dehghanpour P, Shariat M, Dalili H. Caffeine consumption and incidence of hypertension in pregnancy. J Fam Reprod Health. 2013;7:3.

32. Bakker R, Steegers EA, Obradov A, Raat H, Hofman A, Jaddoe WW. Maternal caffeine intake from coffee and tea, fetal growth, and the risks of adverse birth outcomes: the Generation R Study. Am J Clin Nutr. 2010;91:1691-8.

33. Sibai BM. "Hypertension in pregnancy". Obstet Gynecol Clin North Am. 1992; 19(4):615-32.

34. Dodd JM, O'Brien C, Grivell RM. Preventing pre-eclampsia - are dietary factors the key? BMC Med. 2014;12:176.

35. Bakker WW, Donker RB, Timmer A, Pampus MG, Son WJ, Aarnoudse JG, et al. Plasma hemopexin activity in pregnancy and preeclampsia. Hypertens Pregnancy. 2007;26:227-39.

36. Wen SW, Chen X, Rodger M, et al. "Folic acid supplementation in early second trimester and the risk of preeclampsia". Am J Obstet Gynecol. 2008; 198(1)45.e1-45.e7.

37. Yakub M, Iqbal MP, lqbal R. Dietary patterns are associated with hyperhomocysteinemia in an urban Pakistani population. J Nutr. 2010; 140:1261-6.

38. Haberg S, London S, Stigum H, Nafstad P, Nystad W. Folic acid supplements in pregnancy and early childhood respiratory health. Arch Dis Child. 2009; 94:180-4.

39. Hwang J-Y, Lee J-Y, Kim K-N, Kim H, Ha E-H, Park H, et al. Maternal iron intake at mid-pregnancy is associated with reduced fetal growth: results from Mothers and Children's Environmental Health (MOCEH) study. BMC Nutr J. 2013;12(1):38

40. McCarthy F, O'Keeffe L, Khashan A. Association between maternal alcohol consumption in early pregnancy and pregnancy outcomes. Obstet Gynecol. 2013;122:830-7.

\section{Submit your next manuscript to BioMed Central and we will help you at every step:}

- We accept pre-submission inquiries

- Our selector tool helps you to find the most relevant journal

- We provide round the clock customer support

- Convenient online submission

- Thorough peer review

- Inclusion in PubMed and all major indexing services

- Maximum visibility for your research

Submit your manuscript at www.biomedcentral.com/submit

C Biomed Central 